\title{
Expectativas normativas y racionalidades de la penalización adolescente
}

Alejandro Labranque $Z$.

Abogado, Universidad de Chile

Magíster en Antropología y Desarrollo, Universidad de Chile labranque@vtr.net

Resumen

El presente artículo presenta los resultados de una investigación de campo acerca de la delincuencia juvenil y las expectativas normativas presentes.

Abstract

This article presents the results of a field research on juvenile delinquency and normative expectations.

Palabras Clave: Sistemas sociales, derecho, crimen, expectativas normativas, racionalidad

Keywords: Social systems, law, crime, normative expectations, rationality

\section{I ntroducción}

"La finalidad del castigo es asegurarse de que el culpable no reincidirá en el delito y lograr que los demás se abstengan de cometerlo."

- Cesare Beccaria. "De los delitos y las penas" (1764)

La reforma del sistema penal adolescente, publicitada por el sistema político a través de los medios de masas, es caracterizada como un progreso en contraste con el sistema de penalización anterior, y, el de protecciones del antiguo derecho de menores.

Para destacarlo como un avance, y, no como una simple expansión del derecho penal, permitiendo el juzgamiento de personas que antes no estaban afectos a este régimen, se argumenta, desde la sede política, la introducción a las penas corporales de finalidades socialmente aceptables. La pena no es ya el simple castigo, es un proceso complejo que incluye tratamientos de tipo psicológico, rehabilitación farmacológica, e incluso, intervenciones sociales tendientes a la plena integración del infractor.

Por un lado, el origen del derecho punitivo tiene como fundamento la imposición de un castigo, lo que en el estado moderno consiste en la privación del derecho a la libertad individual. Por otro lado, la exigencia de racionalización en la intervención estatal demanda que la sanción sea socialmente útil.

La utilidad social, es aquello que permite la aplicación reflexiva de la pena, resultando en una disminución de la actividad social desviante. Su efecto es la integración social. Ambos paradigmas, castigo e integración social, parecen ser inevitablemente contradictorios. 
Es materia del presente artículo, analizar en qué medida dos o más lógicas tan diversas, surgidas de dominios explicativos con racionalidades contrapuestas, podrán operacionalizarse en decisiones coherentes.

Para estos efectos, primero se describirá someramente el concepto de racionalidad de Luhmann, luego se hará lo propio con la racionalidad propiamente jurídica, se describirán las fundamentaciones locales de la pena, para luego analizar el método lógico por el cual se incluyen o excluyen las distintas racionalidades en la imposición de una pena contenida en una sentencia referida a la materia que nos ocupa.

\section{Racionalidad en Luhmann.}

La racionalidad para Luhmann es una forma de autoobservación de los sistemas capaces de reflexión, que supone previamente que se es capaz de observar al entorno como distinto de sí mismo y aún orientarse a la unidad de tal distinción, poniéndola como contingente, obteniendo de esta manera información.

Así, se somete a verificación continuamente la propia distinción sistema entorno corrigiendo la propia posición en base a criterios construidos en el propio sistema.

Los sistemas de esta manera pueden controlar sus intervenciones en el entorno en base a las repercusiones que estas intervenciones tienen en sí mismo. Esto se puede efectuar utilizando el esquema causa efecto.

De esta manera la introducción de ciertas finalidades al sistema de penalización adolescente (aunque opera no con una lógica de consecución de fines, sino con una de verificación de silogismos, dado A, entonces B), señala un tipo de racionalización que tiende a incorporar reflexivamente el efecto de las decisiones judiciales (en particular aquellas que se refieren al pretendido efecto de las penas sobre la conducta futura del infractor) a las consideraciones mismas sobre la pena, desplazando la distinción sistema entorno, introduciendo un re-entry en la consideración legal de la decisión, que además deberá considerar un efecto probable sobre el entorno (prevención, integración social, etc.). En qué medida ello es posible en base a una racionalidad jurídica que tiene por característica fundamental la contrafacticidad del derecho y en la condicionalidad de la programación del derecho (que no admite la consecución de un fin sino que aplica mecánicamente silogismos) es, como se señaló, materia del presente artículo.

\section{Racionalidad y razonamiento en el Sistema J urídico.}

Las decisiones jurídicas se basan en la consistencia (o redundancia) que ellas tengan con el sistema jurídico mismo a través de su enlace con otras decisiones jurídicas mediante la calificación actual de su validez. Esta calificación de validez se efectúa por el propio sistema mediante su programación condicional (normas), por la que se deducen los derechos aplicables a cada caso de los hechos (variables) que los constituyen, y finalmente esta aplicación de derechos va a consistir en la determinación de si el caso presentado es o no conforme a derecho de acuerdo al código binario universal del sistema jurídico (derecho/ no derecho) ${ }^{1}$. Por lo tanto la intervención de ninguna postura ciudadana en particular, acuerdo o "consenso" de quienes se pueden ver afectados por la resolución, es condición de posibilidad para que una decisión jurídica sea válida (es decir confirmada posteriormente como "conforme a 
derecho"), a menos que el propio derecho establezca aquello como requisito de validez de la decisión.

De esta forma, en el derecho, dada la racionalidad y la forma de evolución particular que presenta (bien en acoplamiento estructural con la política la que introduce reformas legales orientadas a sus propias finalidades, o bien mediante la comparación de casos iguales, aplicando equivalentes normas o de casos diferentes aplicando normas diversas), se operacionaliza mediante "razones jurídicas", lo que no es más que su redundancia con el derecho vigente. Lo anterior puede ser observado por un tercero como un déficit crónico de racionalidad respecto de los efectos que se producen en el lado excluso derecho/ hechos. Lo anterior es explicable porque la pregunta por la racionalidad de los efectos en los hechos (V.Gr. integración social del adolescente infractor) es una consideración científico social, en algunos casos una preocupación de orden político, pero no jurídica.

\section{Contrafacticidad y Racionalización.}

Es decir, el derecho, enfrentado a una sociedad funcionalmente diferenciada, "racionaliza" su distinción sistema entorno a partir de su operación contrafáctica (precisamente haciendo caso omiso a la contrariedad que presenta con los hechos). En otras palabras, podemos preguntarnos desde un programa científico cómo es que un sistema que tiende a la porfía mecánica en términos de la asignación del código binario podría ajustarse precisamente a los hechos que está tratando de estabilizar en forma de expectativas normativas.

Lo anterior significa que en la práctica judicial van a ser pocos los mecanismos que permitan al derecho ajustarse a los efectos factuales de las propias decisiones jurídicas, ello porque se requiere de redundancia legal y no coherencia con finalidades buscadas en la heterorreferencia ${ }^{2}$.

Si se requiere racionalidad en términos de procesos de rehabilitación, integración social o incluso prevención del delito en la persona del condenado, pues bien, deberían al menos asignarse consecuencias legales (silogísticas) a las observaciones científicas (efectuadas desde la psicología, sociología, teorías de la farmacodependencia, etc.), lo que como se verá no ocurre de esta manera, puesto que no se asignan efectos unívocos a tales informes periciales (de hecho no se les asigna consecuencia legal alguna, salvo a su omisión), permaneciendo como una orientación a finalidades que se estandarizan en el tipo de medidas impuestas (las que finalmente son escogidas en base al programa condicional como ocurre con todo el resto de la programación del derecho en sus distintos ámbitos).

\section{Racionalidad de la Pena en la Dogmática J urídica Local.}

La dogmática jurídica, observador/ descriptor de la interpretación y la praxis judicial a la vez que su creadora (los textos de autores reconocidos se citan como derecho), mantiene el sentido de la penalización a disposición de las organizaciones y los funcionarios encargados de aplicarla, ya sean jueces, abogados o gendarmes, lo que puede constituir la justificación de la acción de penalizar para dichos operadores, permitiendo que ello se de bajo un supuesto improbable pero moralmente noble (distinción bueno/ malo), como por ejemplo otorgar seguridad a la población, rehabilitar socialmente al delincuente, lo que desde una mirada conservadora no significará más que el hecho de que el que ha delinquido no continuará haciéndolo, pues aprenderá del castigo y desde una mirada más progresista, la integración plena 
del infractor a la sociedad, mediante una pena reconducida a un tratamiento terapéutico o sociointegrador.

En la dogmática jurídica comparada los conceptos de prevención especial y general no son nuevos, sino que son distinciones ya centenarias (la cita de Beccaria al principio de este artículo data del siglo XVIII). Dentro de la dogmática jurídica nacional, se han recogido estas antiguas tradiciones, que han sido abordadas de generación en generación de autores mediante la condensación de sentido "Teorías de la Pena", de esta manera, Etcheberry (2005: Tomo I: 30 a 35), se pregunta: "Para qué señala penas el legislador y luego hace que el juez las imponga? (...) Dentro del enfoque preventivo, algunos insisten en la prevención general, o sea, en evitar la comisión de delitos por parte de los miembros de la sociedad, y otros en la prevención especial, esto es, en la necesidad de evitar que se cometan nuevos delitos por parte de quien ya ha delinquido (...) Esto se logra mediante su reeducación y readaptación, y si ello no es posible, mediante su eliminación. El delincuente es considerado un enfermo, la pena un bien, y la imposición de la misma, un derecho del delincuente. Los delitos son de exclusiva creación legislativa y la pena sólo enseña al delincuente a gobernar sus actos de conformidad con la voluntad legislativa". Otro dogmático de la doctrina nacional, Cury (1996: Tomo I: 30 a 51), señala: "Frente a las teorías absolutas, las relativas sostienen que la pena sólo se justifica si se la emplea como un medio para luchar contra el delito y evitar su proliferación. Con arreglo a este punto de vista, el cometido de la pena es resocializar al delincuente actuando sobre él para conseguir que se adapte a las exigencias de una convivencia organizada, y cuando ello no es posible neutralizándolo a fin de proteger a la sociedad".

Debe llamar la atención que por lo general, la dogmática jurídica como la citada cumple casi siempre una función normativa (como se señaló, es la interpretación del derecho que puede citarse como derecho al igual que la ley), pero en el caso de las "teorías de la pena", parece existir una cierta desconexión entre la observación efectuada por la dogmática y su descripción del derecho. Ya la sola enunciación de varias "teorías" alternativas y no de interpretaciones que prevalecen unas sobre otras, hace referencia a piezas intercambiables de sentidos diversos e incluso contradictorios que se exponen como plausibles, pero que no tienen la virtud de llenar de contenido la exégesis de la ley. Esto es claro en la práctica jurídico penal adulta, el fin de la sanción no es enunciada en las sentencias salvo de manera excepcional y retórica, no es parte del silogismo, nada fundamenta, así como la rehabilitación del delincuente no anula en lo absoluto la validez de una condena legalmente impuesta (un ejemplo claro en nuestro medio es la indeleble imagen cinematográfica de la "rehabilitación" y posterior ejecución de José del Carmen Valenzuela Torres, el "chacal de Nahueltoro"). En suma, es posible que la irrelevancia argumentativa de la finalidad de la pena, sea a su vez relevancia en términos de la posibilidad de convivencia y justificación cotidiana de los funcionarios penalizadores con su propia labor y ante el contexto social en que deben desenvolverse, así como una declaración de intenciones desde la lógica del sistema político, o bien una finalidad parcial de las organizaciones no atributivas de derechos como gendarmería, Sename, o las policías.

\section{Racionalidad $Y$ finalidad de las Medidas de la Ley 20.084 sobre Responsabilidad Penal Adolescente.}

El 2 de agosto de 2002, se envió a la cámara de diputados el mensaje № 68-347 por el que se iniciaba la tramitación de la Ley de Responsabilidad Penal Adolescente (LRPA), la que pretendía cambiar el régimen hasta entonces existente en materia de penalización adolescente consistente en aplicar la ley penal adulta (código penal) a los 
mayores de 16 años y menores de 18 que eran declarados previamente con discernimiento por el tribunal de menores previa pericia psicosocial en que se determinaban las capacidades del adolescente para discernir las conductas correctas de las incorrectas y penalizadas. Los menores de 16 y mayores de esa edad declarados sin discernimiento, en tanto, eran sujetos de medidas de protección aplicadas por los tribunales de menores.

\subsection{Principios Rectores.}

Las condensaciones de sentido de las medidas establecidas por el texto de la LRPA como finalidades de la pena, no son diferentes a los ya establecidos en la dogmática jurídica de antaño como "teorías de la pena", ya sea en su aspecto retributivo o preventivo general o especial. La novedad de la legislación penal adolescente radica en que se intenta operacionalizar al menos en principio, los referidos principios en las decisiones judiciales prácticas. Las orientaciones finales que la nueva legislación pretende introducir dicen relación fundamentalmente con los objetivos de:

\subsection{Responsabilización del Adolescente y Prevención del Delito.}

El sometimiento de las infracciones del adolescente se expresará en una sanción la que pretendidamente evitará que cometa nuevas violaciones a la ley penal. En este sentido el mensaje afirma que: "Asimismo, las consecuencias jurídicas que se derivan de la responsabilidad de los adolescentes por infracciones a la ley penal, unen a su carácter explícitamente sancionatorio, las funciones responsabilizadora y preventiva...."3.

\subsection{Integración Social.}

Se pretende al mismo tiempo que responsabilizar (atribuir la culpa de un determinado hecho a su autor y sancionarlo por ello) y prevenir (mediante el castigo, el que produciría el desincentivo de la conducta), integrar socialmente al infractor, lo que se lleva a cabo mediante medidas penales especiales, diferentes del sistema penal adulto, tendientes a la resocialización del menor principalmente mediante la regularización de su disciplina escolar, tratamiento de consumo de drogas, todo lo cual se hará patente en un programa de intervención individual (elaborado después de dictarse condena) que tiene por objeto transformar la penalidad en una instancia de reintegración social (aunque no se aborda ni legal ni políticamente como es esto posible en un contexto de estímulos contradictorios (V.Gr. reintegrar socialmente mediante la privación de libertad). Se afirma en este sentido que: "Las respuestas penales contenidas en esta Ley tienen por finalidad, precisamente, "sancionar los hechos que constituyen la infracción y fortalecer el respeto del adolescente por los derechos y libertades de las demás personas, resguardando siempre su desarrollo e integración social". En consecuencia, se considera que tienen una función responsabilizadora, preventiva y orientadora" ${ }^{\prime \prime}$.

Las finalidades que quedan plasmadas en el texto legal y se plantean como requisitos de la construcción de las decisiones judiciales basadas en la LRPA, van a ser las siguientes:

Tabla 1 Finalidades de la Penalización Adolescente en la Ley 20.084.

A. Fortalecimiento del respeto del Adolecente por los derechos de las demás personas e integrarlo socialmente. 
Artículo 2.- Finalidad de la responsabilidad penal. La atribución de consecuencias jurídicas a la responsabilidad de los adolescentes por las infracciones contempladas en esta ley, tiene por objeto sancionar los hechos que constituyen la infracción y fortalecer el respeto del adolescente por los derechos y libertades de las demás personas, resguardando siempre su desarrollo e integración social. $[\ldots]$

B. Criterios de determinación de la pena

Artículo 24.- Para determinar la naturaleza de las sanciones, dentro de los márgenes antes establecidos, el tribunal deberá atender, dejando constancia de ello en su fallo, a los siguientes criterios: [...] f) La idoneidad de la sanción para fortalecer el respeto del adolescente por los derechos y libertades de las personas y sus necesidades de desarrollo e integración social.

$[\ldots]$

C. Condiciones básicas de los centros de privación de libertad.

Artículo 44.- La ejecución de las sanciones privativas de libertad estará dirigida a la reintegración del adolescente al medio libre. En virtud de ello, deberán desarrollarse acciones tendientes al fortalecimiento del respeto por los derechos de las demás personas

[...].

D. Derechos en la ejecución de sanciones.

Artículo 49.- Durante la ejecución de las sanciones que regula esta ley, el adolescente tendrá derecho a: a) Ser tratado de una manera que fortalezca su respeto por los derechos y libertades de las demás personas, resguardando su desarrollo, dignidad e integración social;

Así, la nueva ley pone de manifiesto las finalidades de las medidas penales, aparejando también nuevas complejidades, ya que por un lado la finalidad puede ser contradictoria con la sanción (V.Gr. Cómo integrar socialmente a través del aislamiento que produce la reclusión), o el objetivo puede no agotarse con el tiempo que legalmente se impone para la pena (P. Ej. integración social, tratamiento de drogas o intervención socioeducativa acotada a una pena de 61 días), y por último también exige que los encargados de imponerlas y administrarlas no fueran únicamente especialistas en derecho, sino también expertos en las materias en que se basa la finalidad (por ejemplo, producir una "intervención socioeducativa que fomente el respeto de los adolescentes por los derechos de los demás y los integren a la sociedad).

De esta forma, incluso los plazos penales a los que están sujetas las medidas de la Ley 20.084, no tienen porqué coincidir con los objetivos planteados por la legislación, ya que ellos se determinan legalmente en base a la gravedad legal del delito y no a la necesidad integrativa o socioeducativa, ni aún terapéutica, ni con las finalidades trazadas en un plan individual de intervención elaborado tras la condena, y en un sentido estrictamente jurídico, no se puede revisar la validez de las mismas por el logro o fracaso en los mismos resultados, aunque sí por el cumplimiento o infracción de las acciones determinadas en el plan de intervención, lo que constituye aplicación nuevamente de programas condicionales de tipo legal (por ejemplo, frente a la evasión del condenado puede agravarse su condena, pero no frente al incumplimiento de la finalidad, como la rehabilitación de drogas o la integración socio educativa efectiva).

Sin embargo, no podrá desecharse a priori la introducción de finalidades como una elaboración argumentativa absolutamente separada de lo normativo, ya que la propia ley hace de las finalidades un requisito del razonamiento y de formalidad jurídica, ordenando a los jueces "dejar constancia en su fallo" de dichos criterios en la determinación de la pena, sin lo cual, (ahora sí), se abre la posibilidad de invalidación de la decisión. 


\section{Conceptos expulsados o trivializados en la determinación de la pena.}

Foucault ${ }^{5}$, señala que la psiquiatría y el derecho procesal penal del siglo XVIII y XIX "coevolucionan"6 en torno a la necesidad de prueba que impone el moderno Estado de derecho a partir de Beccaria, momento en que se le imponen restricciones cualitativas y cuantitativas (racionales) al ius puniendi del soberano, se tiende hacia la eliminación de la exposición de la penalización como escarnio público y tiende a hacer del castigo un hecho clausurado en las instituciones penitenciarias. Otra de las limitaciones que se impone a la pena es la disminución de las facultades discrecionales de los juzgadores y la imposibilidad de condena en ausencia de pruebas que acrediten fehacientemente los hechos delictuales. En este sentido la psiquiatría criminal comienza a cobrar importancia fundamental, para recrear una biografía delictiva allí donde la prueba parece insuficiente (es decir permite o facilita la penalización).

Lo anterior da cuenta de que las caracterizaciones psicosociales de las personas que cometen delitos, especialmente aquellos delitos de mayor gravedad, no es nueva, sino que existe una estructura montada desde antaño en torno a la necesidad, no sólo de probar el delito mismo, sino los rasgos sociales y psicológicos que explican tanto la comisión del ilícito, como su probable o improbable reincidencia. En este sentido las pericias psicosociales son una especie de extensión del extracto de filiación y se han manifestado en el derecho penal local adulto por largo tiempo en los llamados "informes presentenciales", los que han continuado en existencia tras la implementación de la reforma procesal penal. De esta manera, si bien la programación finalista de la pericia psicosocial del imputado ha cambiado (desde la caracterización de su peligrosidad a la contextualización de las posibilidades o imposibilidades de su reinserción social), mantiene su carácter probatorio- biográfico, en base a una configuración jurídico- organizacional que la hace posible ahora en un sistema de interaccional (audiencia).

De esta manera, las pericias psicosociales de los adolescentes son evaluadas positivamente por los profesionales de las ciencias sociales (asistentes sociales y psicólogos) encargados de elaborarlas en base a que permiten la introducción de complejidad en un ámbito en que se reconoce la prevalencia de una lógica centrada en la comprobación del delito, más que una que reconozca las causas sociales y psicológicas del mismo (V. Gr. disfuncionalidad familiar, situaciones de pobreza y marginalidad social en la mayor parte de ellos). Pero al mismo tiempo, en el contexto de la implementación de la Ley de responsabilidad juvenil, se puede reconocer por los informantes (dada la modificación al sistema de discernimientos en que la pericia tenía un carácter central y previo al proceso penal), la indeterminación de efectos propiamente jurídicos que aquellas pueden acarrear, especialmente en la fijación de la pena, describiendo incluso el carácter marginal que ya se atribuye al informe en la determinación de la penalidad, como lo señala un psicólogo encargado de la pericia.

E: de los pocos informes que hemos hecho nos pasa que la mayoría de las veces no tenemos contacto ni con los fiscales ni con nada, nos llega el oficio y nosotros

elaboramos el informe y lo enviamos y después no hay un seguimiento, no sabemos si sirven y tampoco tenemos muy claro si en el juicio tiene algún valor, o cual es el valor relativo que tiene digamos en la percepción de los jueces y menos sabemos cual es el destino de los jóvenes [...]

[...] Ahora, es que sabes que si es importante mencionar de que son muy pocas las causas que nos llegan y que cada vez son menos, también entiendo que los fiscales han priorizado pedirnos informes sobre adolescentes en que la situación es bastante más compleja, entonces me imagino que pueden haber muchas situaciones en que la situación no es tan compleja donde el entendimiento y la comprensión de lo que ocurre puede ser diferente, podría pensar que es mejor, que hay más recursos y que esto significó como hablábamos antes un remezón de que "despierta, acá tu también vales" y esos casos no nos llegan, nos 
llegan los más complejos, los que están encerrados, los que están en un juicio con muchas pruebas y por tanto la situación es más compleja

I: ¿una situación compleja sería cuando cometió un delito grave?

E: es que también nosotros hay un tema que no conocemos que es sobre cual es el criterio de los fiscales para pedirnos los informes, ahora también lo que nos pasa que es absolutamente válido que los informes los están pidiendo los defensores, pero yo hipotetizo que los piden los fiscales y los defensores cuando requieren de más herramientas y más pruebas y que por tanto es más complejo, pero tampoco sabemos para que a ellos les es útil el informe, lo que si tenemos una hipótesis un poco más firme porque la hemos contrastado con la realidad es que paulatinamente los informes han bajado y su demanda es mínima, o sea, de 3 a 4 al mes, ahora estamos en uno y hay veces que no nos piden ninguno que es muy alto el grado de no solicitarlo y eso tiene que ver también con qué es lo que esperan los fiscales, o sea, definitivamente hay un quiebre con lo que piden los fiscales y con lo que las normativas del SENAME nos orientan en términos de cuales son los fines de nuestros informes, es decir, los fiscales esperarían muchas otras cosas que SENAME que por su naturaleza y que por su visión plantea que no se deben incorporar en nuestros informes. Ahí un quiebre que está en tensión, que no se ha resuelto, de ver si lo que puede ofrecer el SENAME le puede servir a la fiscalía y a la defensoría $[\ldots]$.

P.19.19. Entrevista Psicólogo Sename.

La indeterminación de efectos de la pericia psicosocial se ve reforzada, como señala el entrevistado, por la normativa administrativa de SENAME, que expresamente intenta apartar los referidos informes de lo que ha sido la práctica del "presentencial" en el sistema adulto, prohibiendo el pronunciamiento respecto de las medidas penales que pudieran adoptarse o no en la condena.

Lo anterior, si bien es explicable como intento de desacoplamiento entre la comunicación psicosocial (cuyo sistema de referencia es la ciencia conducida por la distinción verdad/ no verdad) y el poder (tecnificado en el derecho a aplicar por el tribunal), produce una masa de comunicaciones que caracterizan la persona del infractor, pero cuyos efectos no necesariamente determinan la penalidad asignada en la sentencia (que cumple con sus requisitos de validez enunciando los informes y señalando que se han tomado en cuenta para la determinación de la pena, pero que no necesariamente explica cómo y en que medida esto se ha producido), como se puede apreciar en el extracto de una sentencia penal de adolescentes condenados por un homicidio.

Tabla № 2. Fallo Rit 261-2008. Homicidio Calificado cometido por Adolescentes.

[...] En razón de lo anterior, el Tribunal estimó que la pena idónea para hacer efectiva la responsabilidad de los adolescentes [A y B], por el hecho delictivo cometido e intervenirlos adecuadamente con el fin de lograr su integración social, dentro de las especiales circunstancias tanto familiares, como de estudios y de personalidad que presentan, es la de régimen cerrado con programa de reinserción social, contemplada en el artículo 17 de la Ley de Responsabilidad Penal del Adolescente, en el quantum que se determinará en lo resolutivo, pues permitirá una intervención socioeducativa amplia y orientada a la plena reintegración social, tal como lo establece el artículo 20 de la mencionada ley, ya que con el mérito de las probanzas rendidas resulta claro que ambos jóvenes en el momento de cometer el delito se encontraban refractarios al sistema escolar por problemas de relaciones interpersonales, ambos reconocen consumo de marihuana y carecen de una protección familiar sólida, atendida las especiales condiciones de sus hogares, todo lo que hace aconsejable este sistema de cumplimiento de pena, el que a la luz del mérito de los informes periciales acompañados le han servido para someterse a una disciplina de estudios y diversas actividades que los beneficiaran para la vida de adulto futura, sin perjuicio que en su oportunidad su situación puede ser revisada por el Tribunal competente, si los antecedentes son demostrativos de una evolución favorable en todas las áreas, no siendo tal resolución vulneratoria al interés superior del niño, ya que se trata de una sanción que el legislador ha reconocido dentro de la normativa para casos especialmente graves, estimando estos sentenciadores que justamente éste es uno de aquellos que ameritan su aplicación, teniendo en cuenta la forma de comisión del ilícito, la persona del afectado, su edad, que corresponde a la misma de uno de los acusados, quien vio cortada su existencia en forma abrupta por el accionar de los imputados, haciendo una diferencia entre ambos en cuanto a la extensión de la pena que se les aplicará en relación a su extensión, teniendo en cuanta las distintas edades y la intervención que en la ejecución del hecho a cada uno le cupo [...] Por estas consideraciones y, vistos, además, lo dispuesto en los artículos $1,11 \mathrm{~N}^{\circ} 6,14 \mathrm{~N}^{\circ} 1,15 \mathrm{~N}^{\circ} 1$, 21, 28, 50, 67, 68, $391 \mathrm{~N}^{\circ} 1$ del Código Penal, ; y artículos 1, 8, 295, 297, 325 y siguientes , 340, 341, 342, 
343, 344 y 348 del Código Procesal Penal, 1, 6, 18, 50, 51 y 52 de la Ley 20.084; artículos 1 y siguientes del reglamento de la Ley 20.084 y 600 del Código Orgánico de Tribunales, se declara:

[...] II.- Que se CONDENA al adolescente A, ya individualizado, en calidad de autor del delito de homicidio calificado de [víctima], en grado de consumado, cometido el 13 de Agosto de 2007, en la Comuna de La Pintana, a la pena de CINCO AÑOS DE INTERNACION EN RÉGIMEN CERRADO, período en el cual el adolescente deberá someterse a un programa de reinserción social, bajo la supervigilancia del organismo pertinente y en un recinto especial para menores que el Juez de ejecución determine, debiendo abonarse a su cómputo el tiempo que lleva ininterrumpidamente bajo internación provisoria por esta causa, esto es, desde el 13 de Agosto de 2007, según consta en el auto de apertura.

III.- Que se CONDENA al adolescente B, ya individualizado, en calidad de autor del delito de homicidio calificado de [C] , en grado de consumado, cometido el 13 de Agosto de 2007, en la Comuna de La Pintana, a la pena de SIETE AÑOS DE INTERNACION EN RÉGIMEN CERRADO, período en el cual el adolescente deberá someterse a un programa de reinserción social, bajo la supervigilancia del organismo pertinente y en un recinto especial para menores que el Juez de ejecución determine, debiendo abonarse a su cómputo el tiempo que lleva ininterrumpidamente bajo internación provisoria por esta causa, esto es, desde el 13 de Agosto de 2007, según consta en el auto de apertura.

Como se puede advertir en el extracto destacado y subrayado de este fallo (de 56 páginas), la consideración final sobre la idoneidad integrativa de la sanción impuesta al adolescente ocupa sólo unas líneas dentro de la extensa argumentación jurídica, tendiente a la caracterización de la prueba de los hechos y determinación de las normas aplicables, para este caso, específicamente si se trata o no de un homicidio calificado o simple, agravantes y atenuantes especificas.

Las pruebas de carácter psicosocial de los condenados que consisten en la caracterización de su situación familiar, escolar y social, son citadas en el fallo, pero cabe hacer presente que los razonamientos que tienden a incorporarlo como parte de la decisión judicial, no señalan en qué medida esta caracterización influye en la determinación de la pena. De esta manera, la internación en régimen cerrado es justificada "pues permitirá una intervención socioeducativa amplia y orientada a la plena reintegración social, tal como lo establece el artículo 20 [...]". Se hace patente entonces cómo las decisiones jurídicas orientadas a fines se estandarizan suponiendo dichas finalidades de la aplicación de una norma determinada. En este caso, se enuncia la medida penal (internación en régimen cerrado), a continuación no se hace más que citar el texto de del artículo 20 de la LRPA, y por último se señala que los fines señalados en la norma se cumplen en la sentencia (que además señala ella misma que no vulnera el interés superior del niño), produciéndose una tautología que queda oculta dentro del universo de consideraciones condicionales (no finalistas) de la decisión. El fin de la medida penal se cumple por que es enunciado en la decisión, caracterizándolo (para este caso en particular) tal como aparece en la ley, en otras palabras se señala que consistiendo los fines en aquellos que enumera la ley estos se cumplen por el hecho de haberse tomado esta decisión enunciándolos, lo que no constituye una justificación o argumentación en torno a los fines mismos propuestos con la medida desde los informes psicosociales, sino una mera aserción sobre la finalidad que cumple la medida de internación en régimen cerrado, constituyendo un argumento de tipo circular (los fines se cumplen por que se ha tomado la medida y es la medida la que cumple los fines), sirviendo los informes psicosociales simplemente para dar cuenta que se han tenido a la vista, pero no para señalar cómo y por qué a partir de aquellos es justificable o no la pena impuesta.

A continuación se señalan las razones psicosociales que podrían justificar la medida penal, indicando aspectos de los infractores recreados por las pericias: "encontrarse refractarios al sistema escolar por problemas de relaciones interpersonales, consumo de marihuana, carecer de protección familiar", etc., e incluso, aunque no se señala expresamente, indicando que la medida precautoria de internación provisoria les 
habría servido para "someterse a una disciplina de estudios y diversas actividades que los beneficiaran para la vida de adulto futura".

Sin el contexto de la programación condicional mecánica del derecho, la medida impuesta es ininteligible. Desde luego, la consideración a la finalidad integradora de la pena se basa por un lado en la biografía de la irregularidad social de los adolescentes, por otro lado, en que el "hacer conducta" mientras se encontraban privados de libertad demostraría que mediante una pena similar se les somete a una disciplina de estudios que los beneficiará para la vida de adulto, sin indicar cómo o porqué pueda producirse este pretendido efecto, tampoco señala cómo incide lo anterior en la cuantía de la pena adoptada (solo indica en base al argumento psicosocial el tipo de medida que es reclusión en centro cerrado), asimismo, a pesar que se indica un consumo de drogas, tampoco se impone la pena accesoria de tratamiento de drogas. En otras palabras, la sentencia omite derechamente la explicación acerca de la idoneidad de los medios para producir determinados fines (V.Gr. cómo el confinamiento dentro de un centro de reclusión cerrado produce el efecto de reintegración social, cuando precisamente se les está segregando de la sociedad exterior con dicha medida), para sustituir la racionalidad causal de los medios por la medida misma que se está tomando (la que tiene un carácter legal como la internación en centro cerrado).

\section{Conclusiones}

Ante la indeterminación de la incidencia que las pericias psicosociales tienen sobre la decisión jurídica, la lógica predominante es la de la programación condicional del derecho, en que las medidas penales contenidas en la ley son causa del efecto (también legal), integración social, disminuyendo la contingencia que significaría una verdadera búsqueda de medios adecuados a los fines perseguidos (los que a lo menos deberían estar variando de acuerdo a los cambios favorables o desfavorables del condenado a cada momento).

De esta manera, posteriormente y en base a la sentencia, puede construirse un programa de intervención individual del adolescente pero dentro rígidos parámetros legales, lo que por un lado es una deficiencia en cuanto a los efectos queridos ( $\mathrm{P}$. Ej.: para la reintegración social se tienen como contexto 7 años de encierro forzoso, o bien para un tratamiento de rehabilitación de consumo de drogas en delitos menores de 60 días), pero por otro es una garantía propia del derecho penal, ya que aunque el plan de intervención para dar resultados requiriera de mayor tiempo, al menos se fija un límite que no es traspasable por consideraciones psicosociales. En base a lo anterior, es posible afirmar que las medidas de la Ley 20.084, antes que finalidades sociointegradoras, educativas o de rehabilitación de largo alcance, cumple condiciones legales como cualquier otro cuerpo legal, estandarizando las finalidades en las medidas adoptadas, de esta manera reduciendo la complejidad que significaría para las organizaciones del sistema penal el estar continuamente evaluando si se ha cumplido o no con fines de carácter abstracto en cada caso, o reintroduciendo el fracaso de los fines en nuevas decisiones de manera continua (e interminable). RM

\section{Bibliografía}

1. COOPER MAYR DORIS, 2002. Criminología y Delincuencia Femenina en Chile. LOM ediciones, Chile. 
2. COOPER MAYR DORIS, 2002. Delincuencia y Desviación Juvenil. LOM ediciones, Chile.

3. CURY ENRI QUE. 1996. Derecho Penal Parte General. Tomo I. Editorial J urídica. Santiago de Chile.

4. DURKHEIM, EMILE, 1960. De la division du travail social. Presses Universitaires de France. Paris.

5. ETCHEBerRy ALfRedo. 2005. Derecho Penal Parte General. Tomo I. Editorial Jurídica. Santiago de Chile.

6. FOUCAULT MICHEL, 1973. La verdad y las formas jurídicas. Publicado en en http://www.avizora.com/publicaciones/derecho/textos/0009_1_verdad_formas_juri dicas.htm, accesado en junio de 2004.

7. FOUCAUlT MICHEL, 1992. Microfísica del Poder, Ed. La Piqueta, Madrid.

8. FOUCAULT MICHEL, 2000. Los Anormales, Curso en el Collège de France (19741975). Ed. Fondo de Cultura Económica, Buenos Aires.

9. GARCÍ A PÉREZ, Octavio. “La reforma de 2006 del sistema español de justicia penal de menores" Polít. Crim. № 5 (2008). A1-5, p.1-31. [http://www.politicacriminal.cl/n_05/a_1_5.pdf ]

10. GIDDENS ANTHONY. 2002. Consecuencias de la modernidad. Alianza Ed. Madrid.

11. LABRANQUE ZAVALA ALEJANDRO Y EGAÑA GABRIELA. 2008. El desconocimiento del derecho como condición de su validez. Revista MAD № 18. Mayo de 2008. pp. 102. Universidad de Chile. Disponible en http://www.revistamad.uchile.cl/18/labranque_05.pdf

12. LUHMANN, 1983. Sistema Jurídico y Dogmática Jurídica. Centro de estudios constitucionales, Madrid.

13. LUHMANN, 1993. Teoría Política en el Estado de Bienestar. Alianza, Madrid.

14. LUHMANN, 1998. Complejidad y modernidad : de la unidad a la diferencia. Trotta, Madrid.

15. LUHMANN, 1995. Poder. Anthropos, México.

16. LUHMANN, 1997. Observaciones de la modernidad. Racionalidad y contingencia en la sociedad moderna. Paidós, Barcelona.

17. LUHMANN, 2000. La realidad de los medios de masas. Universidad Iberoamericana, México.

18. LUHMANN, 2002. El Derecho de la Sociedad. Universidad Iberoamericana, México.

19. LUHMANN, DE GEORGI, 1993. Teoría de la Sociedad. Universidad de Guadalajara, México. 
20. MORGAN LEWIS HENRY, 1964. Ancient Society. Ed. Cambridge Mass, Reino Unido.

21. REPÚBLICA DE CHILE, 2000. Código Procesal Penal, Primera edición oficial del 30 de octubre de 2000. Editorial Jurídica de Chile.

22. TEUBNER GUNTHER. 2001. Economics of Gift - Positivity of Justice. The Mutual Paranoia of Jacques Derrida and Niklas Luhmann. Theory, Culture \& Society 2001 (SAGE, London, Thousand Oaks and New Delhi), Vol. 18(1): 29-47

23. TORRES NAFARRATE JAVIER, 2004. Luhmann: La Política como Sistema. UNAM, México.

\section{Notas}

\footnotetext{
${ }^{1}$ Cabe hacer la misma prevención respecto de este código, que hace el traductor al castellano de "El derecho de la Sociedad" de Luhmann (2002: 80- 81). El concepto que originariamente usa el autor en alemán: recht/ unrecht engloba las opciones: derecho/ no derecho; conforme a derecho/ no conforme a derecho; derecho de uno/ no derecho de otro. Creemos pertinente introducir la simplificación adecuada a la realidad local, dado el desarrollo comparativo entre jurisprudencia, doctrina y derecho legal. En este contexto, el código (con todos los significados anotados) es condensable y de más fácil comprensión en la distinción legal/ ilegal. 2 Encontrándose los sistemas en una circularidad cerrada que no niega la existencia del entorno, éste no proviene de un input a la manera de los sistemas abiertos, sino que de una representación del entorno creada por el mismo sistema al que se llama heterorreferencia.

${ }^{3}$ Proyecto de Ley Boletín №: 3021-07. Disponible en tramitación completa en http://sil. senado.cl/pags/index.html

${ }^{4}$ Ibid.

${ }^{5}$ Foucault: 2000: 67

${ }^{6}$ Claramente no lo señala en estos términos, pero sí indica que el desarrollo de la psiquiatría en el S XVIII se debe a su interdependencia con los procesos judiciales y particularmente con la prueba pericial en casos dificultosos (por ejemplo el caso de homicidio cometido por Pierre Riviere o aquellas causas en que el móvil del delito no es claro por que no existen otras pruebas, ni siquiera la declaración del propio imputado).
} 